\title{
Faces and the Invisible of the Visible: Toward an Animal Ontology
}

\author{
DAVID MORRIS
}

An object is an organism of colours, smells, sounds and tactile appearances which symbolize, modify and accord with each other by a real logic that it is the task of science to make explicit. (Merleau-Ponty, Phenomenology of Perception 48/38/45)

The first philosophical act would therefore be to return to the lived world that is on the hither side of the objective world, since it is in it that we will be able to ... restore to things their concrete physiognomy. (69/57/66)

The invisible of the visible. ... There is a Wesen [essence] of red, which is not the Wesen of green; but it is a Wesen that in principle is accessible as soon as the seeing is given, has then no more need to be thought; seeing is this sort of thought that has no need to think to possess the Wesen. (The Visible and the Invisible 300-1/247)

\section{Animality, Nature and Ontology}

Merleau-Ponty often turns to animals for clues to the analysis of experience, nature and ontology. ${ }^{1}$ For example, in the Structure of Behaviour $(S B)$ he discovers conceptual keys to the body and mind not in Cartesian ideas of machines or a geometricized nature, but in animal behaviour as manifesting a dynamic, structural logic in which parts and wholes are implicated in one another in relation to norms. In the Phenomenology of Perception $(P h P)$ he conceptualizes perceived things as having a physiognomic logic kin to that of animal bodies. And in the Visible and the Invisible (VI) and his later lectures on institution $(L I)$ and nature $(L N)$ he begins to explore the thought that being itself, as engendering such phenomena, has a developmental logic echoing that of the animal and the embryo. ${ }^{2}$ 
A phenomenological attitude underlies this strategy of turning to animals for clues: do not begin by fitting phenomena to ready-made conceptual frameworks, instead let the phenomena themselves reveal the conceptual frameworks appropriate to them. But this strategy couples with and signals a deeper tendency, one that Merleau-Ponty shares with or learns from Bergson, namely a suspicion that our usual conceptual frameworks are in fact ill-suited to the phenomena since they are cut to biases woven into our thinking. For example, in $P h P$ Merleau-Ponty remarks that perception is a "violent act" ( $P h P 415 / 361 / 421)$ since it cuts up the perceived world according to perception's demands, whilst hiding these cuts from the perceiver, and it is not hard to think that the empiricist or rationalist presupposition of a ready-made world, which MerleauPonty criticizes throughout $P h P$, is in part motivated by such perceptual demands. ${ }^{3}$ But in his prior work, $S B$, Merleau-Ponty already has such suspicions about, for example, the way the gestalt is conceptualized in psychology. The deeper tendency thus probably antedates or motivates Merleau-Ponty's turn to phenomenology as "a philosophy which puts essences back into existence" (PhP I/vii/vii), a philosophy that works to overcome the biases of our thinking by seeking the core logic of things in the existence of things themselves (rather than sticking with the concepts that we prejudicially bring to things).

Of course this strategy and its conceptual results appear at odds with the usual frameworks of philosophy and science. In recent years a notable tendency has been to conceptualize organisms as products of genetic programs (see Fox Keller, Century of the Gene, Making Sense of Life, Refiguring Life; Cohen and Atlan) and brains as wetware computers, or even to conceive the universe as a computer (Wolfram; Lloyd; Seife). In other words, nature lets us build computers and we return the favour in kind by conceiving nature as a computational system. But this tendency is not really all that novel. Jump back four hundred years and nature's grant of 
clockwork machines is repaid by thinking nature is clockwork. Two thousand years earlier, we crafted nature on the model of human craft. In short, we have tended to model nature on our material or conceptual technology, conforming it to the way we build or think, and thence we think of being not merely on the model of beings but on the model of technological or idealized beings-especially mathematical beings. So it seems odd to work in Merleau-Ponty's direction, which would conform our concepts to nature's animate being-although in recent years some scientists have been driven to ever more dynamic conceptions that seek their model in nature (Smolin; Prigogine and Stengers; Schneider and Sagan; Woese) and some philosophers have emphasized the ontological primacy of living movement (Jonas; Sheets-Johnstone; Barbaras, Le désir, "The Movement of the Living," Vie et intentionalité, "Perception and Movement"). Nonetheless, since our tradition ill-prepares us for working in this direction, the question remains as to what it would be to conceive nature along its own lines, and what nature would look like conceived this way. What would nature be like elle-même, as the French might say, before we conceive it as conforming to our mathematical and mechanical models? Can we find a logic in things themselves? With what sort of logic or principles does nature structure itself, its processes, its interactions?

We might think of this as a post-modern version of a pre-Socratic question. The pre-Socratics sought an archē within nature, but the consequent crystallization of subjectivity, peaking in the modern, cast that archē in the mold of our thinking and thence of our machines and mathematics. How might we now seek an $\operatorname{arche}$ in nature's own terms, an $\operatorname{arche}$ above the turn (as Bergson [184] might put it) where experience is cut up and conceptualized according to pragmatic demands of our thinking or building? Bergson finds this archē in durée. ${ }^{4}$ I want to show how Merleau-Ponty's philosophy, given its tendencies, could find a clue to such an $\operatorname{arche}$ 
in a logic of animality, specifically in a profound and peculiar logic manifest in animal faces. Basically, for an animal to have a face is for a surface of being to become something more than just a surface, to become something that inherently indicates something else, such that (as we will see) being has evolved a zone in which its own essence (Wesen) shines. Such an essence is not some transcendent and purely invisible principle, but is rather an essence in existence, an invisible visible in the visible, an invisible of the visible. The animal face thus is a clue to a logic whereby being, through animate movement, deepens itself through internally inflecting its own essence. It is also thereby a phenomenon that, as shown below, can help us understand the peculiar relation between the visible and the invisible, a relation that is key to Merleau-Ponty's later thinking.

To develop these points, I gradually explicate the peculiar logic of faces, through a study of animal phenomena. I then show how this logic echoes the physiognomic structure of perception that Merleau-Ponty detects in his earlier philosophy, and exemplifies and clarifies a logic elemental to his later ontology. I thereby shed light on the above epigraphs. To handle the question why the logic of the face can manifest this analogy or homology with the logic of perception and ontology, why the face can clue us in to an archē within nature, I turn to embryology, suggesting that the logic of the face ramifies a deeper logic of being. The face is a phenomenon that can reveal a conceptual framework appropriate to the study of nature because the face as natural phenomenon is structured by a deeper movement and logic of being that the face also reveals. The face is something like a lens into the onto-logic of being. This lens lets me suggest that what underlies Merleau-Ponty's later ontology is a sort of logic of animality.

I must emphasize that here and throughout the word "animal" should be read not as a noun but as an adjective designating that which is animate, that which moves and elaborates itself. 
Really, the ultimate focus is not so much on animals (animaux), on animals as substantives, but on what Merleau-Ponty calls (in his lectures on institution, $L I \mathrm{BN} 13-17$, and also in $L N$ ) animalité. I understand animality as a sort of virtual logic that is actualized by animal beings in an exemplary way, but that is actualized by other sorts of beings as well-even by being itself. When I use "animal" as a substantive, it should be read as shorthand for "animal being"-a being exemplifying animality.

In other words, while the discussion below challenges idealist, mathematical, mechanist, anthropic or subjectivist ontologies, it does not aim to replace these with a kind of animism which would say that being is made of animals or is an animal. (Such an animism would once again model being on beings, just a different kind of being.) The point is rather that being and animal beings have a kindred logic of animality, and that animal beings in their animality can clue us into this logic. When seeking to interpret another culture, we would be wise to seek the testimony of an 'informant' whose life is informed by that culture from within. In evolution, animals (including we human animals) leverage the dynamics of being such that animality is informed from within by the structuring power of the way things go. Animals thus stand as internal 'informants' of the dynamics of being. The methodological thought here is that instead of trying to read and articulate the dynamics of being through our machinery or conceptual presuppositions we might read an underlying dynamics of being, its arche , from within, via the testimony provided by animal bodies and movements—including our own animal bodies.

\section{Animal Faces}

Faces are a striking and central feature of the animal world. If I am not mistaken there are no locomotory vertebrate or arthropod animals that lack faces. It seems that the Earthly evolution 
of self-locomoting, rigidified bodies concentrates guiding senses in the animal's forward moving surface, and this means having a face, a way of facing the world. Indeed, on the embryogenetic level the face is integral with the vertebrate body plan and its enervation: vertebrate embryo development is organized around the formation, down the long axis of the body, of a neural tube, which tube is precursor to the central nervous system; neural crest cells migrating through the neural tube during its formation give rise to the neural system and brain but also (via cranial neural crest cells) to the structures of the face including its skeleton, muscles, teeth, eyes, and inner ear (Sperber; Wolpert).

But faces are not merely a central physiological feature of animal bodies, nor are they merely a place where animal perception meets the world in an especially focused way, they are central to animal being, to animals as moving with and against each other, since they are surfaces in which animals show and read one another's behaviour. Indeed, in faces we see something of an animal's basic way of seeing, being seen by, and being with, other animals. There are, for example, flock and herd faces, as in fish, horses and cattle, and flocking birds, whose side-placed eyes are good for seeing wingmates when moving together as a flock in face of the world. There are loner and confronting faces, as in predatory birds, human and non-human primates, cats and dogs, whose forward facing eyes are good for seeing prey or facing one another. There are also swarm faces, as in insects whose compound eyes are good for seeing in three dimensional swarms. And other dimensions of animal relations can be read in the face's abilities of smelling, hearing, touching, picking up heat, vibration and pressure, and so on. ${ }^{5}$ An animal's face thus shows that the animal is to be perceived and seen. This is a central point in the philosophicallyinclined zoologist Adolph Portmann's studies of animal appearance (Animals as Social Beings, Animal Camouflage, Animal Forms and Patterns, Essays in Philosophical Zoology), which 
Merleau-Ponty discusses in his nature lectures ( $L N$ 244-8/186-90) and which we come back to below. If a hand meant to touch another hand is a signature of reversibility in the register of the tangible, a seeing face that is meant to be seen shows a reversibility within the visible. A facelike a painting (see Merleau-Ponty, "Eye and Mind")—-makes explicit that seeing and being seen are not two separate things, but are part of one circuit of being. This means, though, that in animal terms faces are not just physical surfaces. The face of a given animal is a surface whose animal being implicates it in something 'exterior' to it, namely the perception and vision of other animals, more broadly in the realm of exterior animation as a whole.

More important for our purposes is that the face also implicates something 'interior' to it, namely the given animal's animality, the animal's movement and tendencies as something further than and beyond the facial surface, which can, nonetheless, be read in that surface. Indeed, this realm of 'interior' animation is only manifest as such insofar as it surfaces in 'exteriority,' in the face broadly construed. Here we get an inkling of the peculiar logic of the face, a logic of animality that, as we will see, mixes the interior and exterior, thus challenging our conceptual tendency to easily divide them. What is really striking about the face, in other words, what pre-occupies us below, is not simply the centrality of the face to the empirical phenomenon of animal bodies and behaviour, but something conceptual, a peculiar logic implied each time a face is grasped or operates as a face. What is even more striking is that this logic of faces is so obvious and taken for granted that we usually overlook it.

My task is to let us be struck by a difficult logic that is staring us right in the face. In keeping with my initial remarks, my strategy for achieving this is to let the face itself show its endogenous logic. I do this by having the face confront us with its details, which are worked out through several overlapping studies of the faces of animals, including we human animals. ${ }^{6}$ I do 
this gradually, spiralling into the central issue, because-and I cannot emphasize this enoughthe logic of the face is profound: catching the back and forth relations, reversals and complexities revealed in the face is much like finding beneath the easily grasped words of one's language the vast depths of différance.

\section{The Logic of the Face}

To begin our study it is helpful to remember that our word "logic," which we on first glance take as designating the abstract science or principle of thinking, derives from the Greek word "logos," which is notoriously untranslatable, partly because it has a host of connotations far broader than suggested by current usage of the word "logic." In earlier non-philosophical usage, "logos" has the following connotations: the account of something, a story or narrative; the worth or esteem of something; the process of thinking something over by weighing its pros and cons; a cause, reason or argument for something; the truth of the matter as opposed to its pretexts; the correspondence, relation or proportion of terms; words and language. In philosophical usage, it acquires the connotation of a general principle or rule; the faculty of reason; a formula for something (see Guthrie 420-24). Informed by the Greek sense of "logos," we might broadly grasp a logic as that which accounts for the balance or structure of relations that makes something worthy of being what it is, or that which, in its effects, gives an argument for a thing being the way that it is (as in the argument of a novel). Thus we might talk of the logic of somebody's success, meaning by this the structural pattern of their doings as accounting for their success; or a logic of betrayal, failure or contradiction as inevitably effecting someone's downfall; or the tensile logic of pushes and pulls leveraged by a geodesic dome as the reason for its staying up. In thinking over such phenomena, we start formulating these logics in words, in 
ways that both play upon and highlight the faculty of reason. Eventually our formulae might end up being dominated, shaped by and conflated with our reason, its achievements, its structure, its words-with our tradition and its encrustations. This formulaic logic, logic in the more usual sense, would be contrasted with a broader logos, a reason, spelled out in and by things themselves, a way things themselves have of accounting for themselves through their way of structuring their relations and telling their own story.

What I am contemplating here, for reasons suggested at the outset, is a logic in things, a logic there before the formula. I am seeking a clue to it in the face as telling its own story, as being its own logos — as what Merleau-Ponty might call a wild logos. Of course, I am doing this in words. So it might help to think of the face as a logos that is its own word, a wild word that is tamed when formulated in our words and tradition. But if the face as wild logos could speak in our tongue, the word that it would be, as we shall see, is both "of" and "as," a wild "of/as" that at once echoes the complex logic of relations that we express with the words "of" and "as," yet bewilders our usual ontology and thus serves as a clue to a different ontology.

We can start exposing the logic of the face with a simple but remarkable observation. An animal face is the face of a body, and expresses the whole of that body. This is vivid in the human case: I face all of you in your face. When I look at your face I don't just see your face, I see you, your feelings, your thinking, your attention, a further whole of you, shining in your face. This is also the case with other animals. In the facial movements of Fergus the dog, I do not just see fur, lips and other surfaces moving about, I see his recognition of me as a familiar, his nervousness in face of my hesitations, his friskiness or his sullen non-involvement, motivated by his deteriorating hips. This recognition, nervousness and non-involvement speak of Fergus-as-awhole, something beyond his face merely. I also see in dog, cow, deer, rabbit, horse, orang-utan, 
parrotfish, octopus and stingray faces their seeing of me as something more than just a surface, their seeing of me as an animal scanning ahead, planning to move, an animal threatening or nonthreatening. ${ }^{7}$ Of course, I see this not just in the face in the usual sense, but in the animal body as a whole - the whole body serves as what I call a "greater face." I get at the logic of the face both through the face in the usual sense and through the greater face.

All of this is utterly familiar but intensely wondrous, because it shows that the face is a surface inherently beyond itself, a surface permeated by a further body of which it is the face, a body that shows up in and through the face. Yet, in the face this body does not show up as a mere material body would, as a moving mass of objective flesh. The face gives its body a new visibility, a way of showing up as something animal, as an animate whole. This is the nub of the logic of the face: the face is a peculiarly transformative translation of the body, it shows the body as a moving animal whole. The complexity lies in the peculiarities of this of/as relation. I dig deeper into this complexity by analyzing a series of animal phenomena, starting with Portmann's observations of animal form.

Portmann notes that in animals (mostly frogs and fish) with transparent flesh, internal organs tend to be wrapped in an opaque sac, a physiological structure that is not found in nontransparent animals (see esp. Essays, also Camouflage and Forms and Patterns). Because of this, when looking at such animals, we see, through their transparent flesh, a smooth, symmetrical, uniformly coloured sac in visual harmony with the animal's overall shape, rather than seeing a colourful spaghetti of innards. This emphasizes, Portmann argues, that animals are meant to be seen, a claim central to all of Portmann's writings on animal form and colouration. Animal surfaces are not simply waterproof or insulating barriers, they have more than a physiological function, for surfaces make a difference as to how animals look. In transparent animals, this 
surface that other animals look at is interior to the transparent skin, rather than being at the skin itself.

Let us consider some further observations of Portmann. The hummingbird's iridescent colours are not due merely to pigmentation but to minute variations in physical structure, as in the shimmering colours of an oil slick (which colours are caused by slight variations in the slick's thickness). In the hummingbird these effects are produced by modifications in the development of the barbules of the feather (barbules are the tiny individual branching featherstrands). What is notable in the hummingbird is that these physical modifications only occur in the outermost, visible parts of the feather, not in the inner part of the feather, which are covered and made invisible by overlapping feathers. Similarly, in some duck species, individual wing feathers are striped to one side of the shaft but are blank of striping on the other side; but in the wing, the blank side of a feather is overlapped by the striped side of another feather, so the feathers as a whole display a continuous striped pattern. These evolved modifications to feathers clearly have nothing to do with flying or warming functions, and since there are different modifications in the visible and invisible parts of the feather, these differences have clearly evolved in relation to the animal's overall visibility. Visibility, not just local function, is an issue in animal evolution. This is emphasized by the coloured sac around the organs in transparent animals because the sac is of no physiological benefit to the animal, and has not evolved in opaque animals. Its only function, according to Portmann, could be the way it makes the animal look to another animal.

More recent studies (Ruxton, Sherratt and Speed) muster evolutionary evidence suggesting that transparency confers a survival advantage. Transparency helps animals hide in their environment - a phenomenon called crypsis. Part of the evidence is that the refractive index 
of transparent flesh is close to that of water, so in water, light rays travelling through transparent flesh barely deviate from straight lines. In water, then, light rays travel through transparent flesh without much deflection and such flesh is not easily visible_-in water, other animals see (nearly) straight through such transparent flesh. On land, the difference between the refractive index of air and of transparent flesh would cause light rays to bend through flesh, and so transparency would be less effective as crypsis. But transparency is only found in aquatic (or amphibious) animals, which suggests that cryptic function is key to the evolution of transparent flesh.

Ruxton, Sherratt, and Speed also note that while the flesh of living animals can be transparent, dead or digested transparent flesh loses transparency (because the cellular organization that enables transparency is destroyed). Even if the gullet of a transparent creature were transparent, digested food in the gullet would become non-transparent. I would suggest that with respect to crypsis, the opaque sac hides the food the animal digests. While the animal can hide itself by making some parts of its visible body transparent, it cannot so hide what it eats. (It also cannot hide its eyes, for the pigments and tissues required for capturing and stopping light are inherently going to be visible. As Merleau-Ponty might put it, the condition of seeing is being seen.) The opacity of the sac lets the organism control the visibility of digested food that it cannot render transparent. The sac literally encrypts the food, burying it in a crypt.

This brings us closer to the peculiar logic of the face, for we would have to note that the sac's function is therefore not achieved in the sac's own material, but in a relation that stretches beyond this surface to the innards it envelops. The sac's function is to screen innards, ensuring that innards are not visible in their own terms; but really this means the sac's function is to make innards be outwardly visible in a different way, to encrypt them, to hide them in plain sight as a coded message conceals its content. The visibility of the sac predicates invisibility of the innards 
and of food: it 'shows' the innards as something not to be seen, as something to be hidden. The sac, as part of the animal's greater face, thus operates as a logos of its body: it tells the story of its body, gives an account of it, it gives the argument of the animal's way of life (at least in part), in the way that the novel gives the argument of its protagonist. A zoologist who does not see that the transparent animal argues for its own concept of itself in the way it makes itself visible is not really grasping the animal as a living orientation to its environment, and is thus not really grasping an animal—an animate, lived body, a Leib_-but merely a Körper, a body as object.

The paradoxical logic of the face now comes to the fore. The animal Leib-in this case the transparent body which makes itself invisible in order to hide its life from other animals-is nowhere to be seen except in the story told of it by the animal's greater face as something visible. Put otherwise: The sac pertains to the body, it is the logos of the body. It shows the logos of the body as a body to be hidden. But the logos that shows this is also engendered in, is of, the very body modified by this logos and by the as relation. What we have here is a logos within a being, a logos that modifies a being from within. We have a being that from within itself 'doubles,' a being that within itself shows itself as not being its matter merely, but as 'doubled', because it has a different essence (Wesen), a different thing that it is to-have-been, beyond its mere matter. The transparent animal leverages the optical properties of matter in order to be hidden on an animal register of visibility that is beyond the merely optical or material. Yet: this "beyond" has its being nowhere else than in matter that moves in an animal way and that, as animal, evolved a greater face through which it shows its "beyond" in its own depths. The hiddenness of the animal is 'doubled' right on 'top of' its optical visibility.

In the language of subject and predicates, it is not as if the transparent animal's logos predicates something (hiddenness) of an animal subject already there in advance of and naked of 
this predicate, or as if, on the other hand, there could be a predicate of hiddenness in advance of the animal subject engendered by this logos. In other words, in general a facial logos and its subject are not two things. It is not the case that the facial logos adds independently existing predicates to a body that already stands as animal in advance of its predicates. The facial $\log o s$ is a sort of deepening or inflection of the body (an internal 'doubling'), a deepening that first engenders the body as showing inner depths of animality. This relation poses a challenge to an ontology in which the subject and predicate would be distinct and in which the subject would be a purely invisible substratum or hypokeimenon, a bearer of predicates without any predicates of its own, for the animal subject is only there as animal insofar as it predicates (for example) hiddenness and animality of itself. This relation also challenges an ontology in which essences are in a transcendent beyond: the animal shows its animal 'essence' within itself. The paradoxical logic of the face thus manifests something ontologically significant, for it is the logic of an invisible of the visible, of invisible depths of the visible that are, however, nowhere else than in the visible, specifically in the face as the visible of the invisible (in the face as that which makes the invisible visible). We shall return to these ontological points. I now want to both temper and ramify the complex logic we are tracing, by working through further examples.

When I curl up in the morning with blanket and book on the sofa of my friends, their cat Charlie will near inevitably come to nestle in the crook of my legs, stretching out to be petted, blinking at me as she arches her head and back away from her stomach. In a remarkably detailed phenomenological analysis, Elizabeth Behnke writes of being taught by her cat Sheba "to return a blink" and notes that "an exchange of blinks is a well documented greeting ritual between cats, with the interruption of the gaze by the blink indicating a willingness to establish and maintain 
friendly relations and mutual respect" (105). In a phenomenological study of the intercorporeal nature of bodily expressivity, Kym Maclaren writes that:

...Gregory Bateson has argued that the "instinctual" rituals, that two dogs, for instance, enact in meeting and greeting each other are not instinctual in the sense of being preprogrammed and automatic circuits. The rituals are rather a matter of the two dogs expressively and intercorporeally determining the situation, and working out a shared world. Animals, Bateson asserts, cannot use negations. They cannot say "I will not bite." What they do, instead, is they act out a kind of reductio ad absurdum: they play at biting and fighting, for instance, in order to reveal to each other that "it is biting that I am not doing." In this way, they "discover or rediscover friendship." (250)

The cat ritual of blinking would seem to share the same underlying logic: in interrupting the gaze, Charlie reveals that it is gazing at me as a potential threat or rival that she is not doing. In this way she shows she is relating to me not as a threat or rival, and not as threatened or rivaled by me, but as a friend (and wanting to be petted). (Note that we humans do similar things: when two rivals stare each other down, one might "blink first" and back off.) Two points are of note here. First, as in Bateson's example, the logos (the meaning and underlying structural logic) of this gesture is inherently intercorporeal. For Charlie's blink to have the meaning of inviting friendship it must interrupt a mutual, intercorporeal gaze between possible animal rivals. Second, I said above that when Charlie blinks, "she is relating to me not as a threat or rival ... but as a friend" (emphasis added). The important point here is that her blink reveals a "she," a "Charliecat' who is much more than just her blink. The blink reveals a suite of movements (comportments of friendship) counterpart to and implicit in the blink, sequel and prequel to the blink, movements that are not the same as the blink yet are gathered together and revealed as friendly right in the blink. So the blink is not merely a superficial add-on that signifies an animal body that would already, independent of the blink, be friendly. The blink makes possible a show that gathers together friendliness, that makes friendliness an explicit intercorporeal issue. The 
blink and the friendliness are not logically external to one another. Whither the internal relation of the blink and friendliness? Recall that the friendly logos of the blink is intercorporeal, implicated in the blink's interruption of a relation to another's gazing body, and is thus dependent on and rooted in other bodies. But it is also intracorporeal, implicated and rooted in a relation to a moving body further to the blink (Charlie's body as 'behind' the blink, as that which the blink is the friendliness of). This further moving cat-body, though, in turn implies a blink (or other gesture) through which it shows up, a blink that makes visible a logos of bodily friendliness that would otherwise be invisible as such, or more accurately, would otherwise not even register or be an issue at all, be neither visible nor invisible.

The blink is the visible of an invisible (of a friendliness that cannot be directly presented in any simple given, immediate visible surface), an invisible that would not even be invisible without its visible (the blink) that gathers and shows it. So this invisible (the friendliness) is thus of the visible: it is an invisible implicated and engendered in the visible through which alone it is revealed as such, it is an invisible that shows up in depths generated within the visible. Just as the dog ritual of not biting can only be performed across two bodies, the cat ritual of blinking can only be performed across a depth between a face and a body further to it. But the depths of this further body are, paradoxically, only revealed as such, engendered, in the face.

Portmann's observations prompt a thought experiment that helps with this point. Imagine that our skin and faces were transparent, showing our organs. Imagine me trying to understand you by looking into your innards, as someone divines the guts of birds for signs; this would be incomprehensible. It is rather because your surfaces are opaque, and because this surface opacity concentrates in your highly mobile face, that I can have a gut feeling about you and your feelings. It is because I cannot optically see your innards that I can see some depths of your 
being on the surface, through your face. Much as Merleau-Ponty ("Eye and Mind" 182) notes that you do not see tiling as being on the bottom of the pool despite the water and undulating reflections, I see some of the depths of your being, what might (wrongly) be called your interior states, not despite the undulatory opacity of your face, but because of it. The paradox is that the depths of your being are shown nowhere else than in the surface of your face (and greater face), but that these depths are nowise the same as that surface-and yet are not somewhere else. Again, in the face we see a being inflecting itself, engendering its own interior depths. (MerleauPonty would speak of such an inflection in terms of a hollowing. ${ }^{8}$ )

The depth in question here is something metaphysically peculiar. Once again to MerleauPonty. He writes of the paintings at Lascaux that they are not there on the surface in the same way as the cracks of the wall, but they are not elsewhere either ("Eye and Mind" 164). You do not so much see a painting, as see according to it; you see the painting not as pigment on a surface, but as what it is a painting of. Similarly with the face: if you just see it as surface, you are not really seeing a face; you have to see through the face, according to it, you have to see who it is the face of. For Merleau-Ponty, painting is metaphysically significant precisely because it is not simply present in its surface, because it presents a depth in a surface. The depth in question is not a distance between points in an already constituted system, it is a depth instituted and made possible by that surface, a depth of a surface. So too with the face. Even if Mona Lisa had never existed in depth as a physical body, painting her face would still open up the depths of her being, a who, within a painted surface. Closer to our point, Alice remarks of the Cheshire cat (when it vanishes from tail to head, leaving a lingering grin) that "'I've often seen a cat without a grin'... 'but a grin without a cat! It's the most curious thing I ever saw in my in all my life!’” (Carroll 67). But what she really is seeing is a grin that is in itself of a vanished cat, or more 
precisely a grin that is curious because it does not show the cat body of which it is nonetheless the grin. But we need not turn to painting and novels for testimony on this point, for one form of animal crypsis (see Portmann, Camouflage; Ruxton, Sherratt and Speed) plays on precisely this depth aspect of the face, as, for example, when butterflies evolve wings with eyespots that make them look, to other animals, like faces of birds: the depths of the bird are there within the 'fake' face - not a grin without a cat, but an avian gaze without the bird. The face, as letting us see something further than the face, which can yet only appear within the facial surface, institutes a metaphysically peculiar depth dimension, akin to that of painting. It institutes an invisible within the visible, an invisible of the visible.

To venture a summary, which will not however capture all the back and forth complexities suggested above and that would remain to be traced in the face: An animal face is of (about, but also engendered of) the animal depths that it shows. But it is also that which first of all shows these depths as animal, it manifests or institutes a depth of animality within an animal being by letting those depths surface in the face-but the depths that surface are not there in advance of or apart from their face.

Recalling that this showing of animal depths in animal faces is a showing of these depths to other animals, we can link this point with Merleau-Ponty. In VI he writes that as soon as "we see other seers," as soon as we experience our bodies as coupled with a world and with others who locate us in a place from which we see, we experience a body that makes itself "the outside of its inside and the inside of its outside" (VI 188-9/143-4). The point traced above is that the face itself manifests this logic of the body being "the outside of its inside and the inside of its outside." The logic of the face thus contests the ontological division between interiority and exteriority that Merleau-Ponty challenged from $S B$ onward. ${ }^{9}$ A face grasped as such manifests 
the body as a 'doubling' back on itself, such that an interior 'essence' is inflected within it and shines in it externally. In short, the face is a visible exterior that manifests interior, invisible depths, which are not, however, purely invisible, nowhere to be seen, because they precisely show themselves in the visible — an invisible of the visible.

\section{Faces and Perception}

We are now in a position to grasp how the logic of the perceived world is kin to the logic of faces and how things thus have a "physiognomy" and are "organisms of colours, smells, sounds and tactile appearances," as Merleau-Ponty writes in the Phenomenology (69/57/66, 48/38/45).

In the "Primacy of Perception and Its Philosophical Consequences" (13-14), Merleau-Ponty rehearses the Phenomenology's view of perception through a discussion of perceiving a lamp, beginning from the simple but remarkable observation that a lamp has hidden sides that cannot be seen but nonetheless are sides of the lamp. The hidden sides are not represented by me, they are not there as belonging to some ideal lamp of which it "is true that the lamp has a back," in which case I would, on the register of truth and the ideal, grasp and have present to me the lamp in its entirety, with the backside merely operating under a different cognitive sign than the front. It is no mere epistemological or truth claim that the hidden sides are there, they are there. The hidden sides are present, but present in a different way than the visible side — they are present as eluding and escaping full presence. Indeed, Merleau-Ponty's profound point in PhP is that the reality and veracity of things, their truth as things, hinges on the impossibility of grasping or having them be present in their entirety. Truth hinges on a perceptual inexhaustibility. This inexhaustibility could not of course be fully presented all at once or in exhaustive detail. Yet, 
paradoxically, this inexhaustibility is indicated in aspects that things do make present to us. Thus when I see the lamp:

I grasp the unseen side as present, and I do not affirm that the back of the lamp exists in the same sense that I say the solution of a problem exists. The hidden side is present in its own way. It is in my vicinity ... [Perception] reveals another modality which is neither the ideal and necessary being of geometry nor the simple sensory event.... ("Primacy of Perception" 14)

I want to say that the modality of the back of the lamp is cognate to the modality of the body of the face. The back of the lamp is there as missing in its front side in the way that the animal body of the Cheshire cat is there as missing in its vanishing grin or as the friendly animality of Charlie-cat is there in her blink. The logic of the in-principle inexhaustible relations between the perceptual aspects of real perceived things (as opposed to hallucinated, illusory, idealized or imagined things) is cognate to the logic of the face: the face and its body are in principle irreducible to one another, cannot be exhausted by each other, yet are inseparable from each other; the body as inexhaustibly beyond the face depends for its very inexhaustibility on its divergence from a face from which it cannot, however, be separated. The front is the front of the lamp, and as (merely) front of the lamp, it shows the lamp as lamp, as having further sides, in the way that the face is of the animal, and as the face of the animal shows the animal as animal, as having a further inexhaustible animality manifest in the face.

The front of the lamp is not merely the optically visible front of an object the back of which is optically invisible, nowhere to be seen. Merleau-Ponty's point is that the back of the lamp, and thence the lamp as whole, are seen in the front of the lamp, but in a different way and as having a different sort of modality than the front. The front, as internally enfolding further aspects of the lamp, thus makes visible (not merely in the register of physical optics, but in a 'doubled' register of perception and being) what would otherwise be neither visible nor invisible, what would 
otherwise not even register, namely: the lamp as a whole, a lamp 'essence'. The front is the visible of its invisible. And the lamp, insofar as we can see it in its front, is the invisible of the visible, the lamp is a whole that—even though we cannot see it directly-is not off in some idealized geometrical realm but is invisible, is showing its non-showing, right there in the visible. To see a lamp in its front, or to feel the density and weight of a wooden cube by hefting and knocking its side, is very much like seeing a cat in its face-the perceived thing and the animal are structured by cognate logics.

So Merleau-Ponty's claims about the physiognomy and organismic character of perceived things are more than mere metaphor. Perceived things do manifest an animal logic.

But at this point an important qualifier is needed. It is very tempting above to speak of the face of the lamp as being the visible of its invisible, and so on, to say that the lamp's front is its face. That would, after all, be the natural way to put it in English, in which we speak of the side of thing that is most visible and closest to one (the side facing one) as a face of the thing. But the fact that perceived things manifest a logic that is cognate to the logic of animal faces does not mean that things have faces in the way that animals have faces. For one thing, a thing's front can be taken as merely a front, it can be physically or conceptually separated from the thing, as when we physically or mentally detach the front of a house from the house. For another, the side that stands as a thing's face keeps changing as different sides of it face one. Neither of these points hold for the face of an animal, for the face proper. The animal face in its very being as face insists on its integrity with its body: the separation of the face and its body leaves us with a face in name only, or nightmare cinema. ${ }^{10}$ And the aspect of the animal that is its face is fixed, rather than being variant. In other words, the animal's face is its face for the animal itself, whereas the thing's front stands as its face for the perceiver. On this analysis, when speaking of the faces of 
things, we are, strictly speaking, using a word that sounds the same yet is different than the word we use to speak of animal faces. So we can speak here of "thing-faces" versus "animal-faces." (When I use the term "face" without qualification I mean "animal-face.") Yet the fact that we actually use words that sound the same for these two cases suggests that the English language has grasped that the two cases have cognate logics, have similar operating principles. We are left with a question as to the relation between the two cases: Is there something more than cognate or analogous logics here? We will have to come back to this question—and this will complicate our point.

\section{Faces and Ontology}

I now want to explore a far more daring thought: that being has a logic of animality. Elizabeth Behnke insightfully notes that Merleau-Ponty's later philosophy is a criticism of what she calls "frontality," an attitude in which nature, being, space, duration and so on are posited as objects over-against a subject who surveys them from above or the outside, and in which nature is posited as a totality of things that are spread out outside of one another, with no internal relations (95). Frontality posits things as fronts that have no further depths, as things that stand solely within themselves as fronts for other things. What we have seen above is that, remarkably, Merleau-Ponty's criticism of frontal ontologies is already implied in his analysis of perception and his view of perceived things as "organisms," since his point is that, for example, the front of the lamp does not stand in a frontal relation (in the above sense) to the back of the lamp, because the fronts and backs of perceived things are internally related in the way that faces are internally related to bodies. What is even more remarkable is that we can find this criticism embodied in the wild, for Merleau-Ponty's point is already implied in the very logic of faces. Faces are an 
original clue to the refutation of the logic and ontology of frontality for they are, as we have seen, not fronts over-against something external to them, they are inherently of, endogenous to, that which they front.

Faces thus limn, in being itself, in the wild, a central and difficult figure of the ontology that Merleau-Ponty is working out in The Visible and the Invisible, namely: the invisible of the visible (see VI 274/220, 300-1/247, 305/251). The logos of things, and of being, is not something directly visible or perceivable, as is, say, the red light bouncing off the carpet. The logos is in this sense invisible. But this does not mean that the invisible logos is purely invisible, nowhere to be seen. The invisible $\log o s$ is seen nowhere else than in the visible, its invisibility is visible in the visible. For example, the visible red light glancing off the carpet shows itself to us not just as red, but as the redness of a carpet, it shows an 'essence' of red. The visible red thus inflects itself, deepens, into a redness which is not visible in the same way as the red light. But this invisible redness is seen nowhere else than in the red. And according to Merleau-Ponty this is not because our thinking projects a redness into things, it is because red itself deepens in this way, it is because being itself is inflected with its own depths. (On the example of red and the carpet, see VI 173-5/131-3.) The invisible is thus of the visible-it is an invisible of and within being, an 'essence' that shows itself right within existence, rather than an invisible beyond being.

This onto-logic is obviously quite paradoxical and difficult. But the logic of the face and the ontology behind it prepares us to grasp this onto-logic because the two logics-of the face and of the invisible of the visible_-are, I suggest, kin. Anyone who has seen a face as a face and is prepared to trace out its curious logic can see, at least on a superficial level, what MerleauPonty is up to when he says there is an invisible of the visible: the plain fact is that we see an invisible of the visible each time we see a face as showing something further to it that is not yet 
the same as the face, yet is the very sense of the face. The redness is seen in the red in the way that the friendliness is seen in the blink. (An objector could argue that the friendliness is seen in the blink only by way our projecting it into the blink, and likewise with the redness. But our analysis above insisted that the friendliness is not there in advance of or apart from the blink. The blink is the phenomenon through which alone friendliness can show up as such, although it is not identical with the friendliness. Friendliness is no mere projection, it is internal to the blink, yet different than it. Similarly, Merleau-Ponty's emphatic point in $V I$ is that the redness is no mere projection but is in the red. What we are tracing here is a version of the paradoxical logic of Merleau-Ponteian expression (see Waldenfels). The blink expresses the friendliness. And as I suggest below, Merleau-Ponty's view in VI is more or less that the visible expresses invisible essences.)

The question, of course, is one just raised with respect to faces and perception at the end of the last section: Is this link between the logic of faces and the onto-logic of essences, the onto-logic of the invisible of the visible, anything more than an analogy? Again, we will have to come back to this question. But to better appreciate the ontological issue at stake here, I want to link these remarks to an issue that has been haunting philosophy for a very long time. What haunts philosophy is the need for what I call the impure invisible. Merleau-Ponty suggests the visible is impure when he thinks of the invisible as being of the visible. I explain the impure invisible by showing how it challenges traditional essentialism.

First, classical essences are pure invisibles. In Plato's Republic key passages are concerned with telling the difference between things and their real look. ${ }^{11}$ We can see, for example, that a hand-drawn triangle looks different than the triangle's real look, but we cannot quite see this real look itself, the eidos of the triangle, its essence. Ideas, essences, would seem to 
be purely invisible. Plato, I suspect, is up to his usual tricks here and he in fact anticipates an invisible of the visible. ${ }^{12}$ The point, though, is to entertain a plausible locus classicus for the terms the visible and the invisible, and it is quite clear that what is already at issue in Plato, Aristotle, and the neo-Platonists (with their doctrine of the overflow of the invisible "one" into the visible) is the of relation: how is it that the visible is of the invisible? How are visible things related to seemingly invisible forms, ideas, essences? (Note that the usual take on Platonism presents an ontology of frontality: things are merely fronts for the real things, ideas, which ideas are (seemingly) external to things as mere fronts-but this ontology breaks down around this externality and the of relation, leading, say, to the neo-Platonist "one" which fronts itself through overflow.)

Second, the intimacy of the visible and the invisible is central to Husserl's concept of the intuition of essences, the Wesensschau, which is meant to revise the classical Platonic conception of ideas. Husserl's claim is that essences, even categorical essences, are given through intuitions, via a process of variation (Husserl; Levinas). To see the front of the die as such is to see it as foreshadowing an invariant flow of variant sides. This invariant flow specifies an essential core of the die. The essential core is not directly visible in the front of the die, but it is not purely invisible either, since it appears through the die-front. The visible die-front has its invisible, the essential core that it foreshadows. And the invisible has its visible, since the essential core appears only through the die-front. The die-front functions like the sac that adumbrates the hiddenness of the animal. But on this view of Husserl's, all essences, even of mathematical objects and so on, appear as invisible (phenomenologically inapparent) invariants adumbrated in visible (phenomenologically apparent) variations. In Husserl the invisible and the visible are intimate (thus challenging an ontology of frontality), and so the invisible is impure. But in 
Husserl this intimacy (this 'doubling' of the visible, or the invisible's distance from the visible, as Barbaras ("Life and Perceptual Intentionality," Desire and Distance) might put it) is first of all anchored in consciousness and bodily kinaestheses. ${ }^{13}$ Merleau-Ponty's project in The Visible and the Invisible is to root this intimacy in the soil of being or nature itself, so that the philosopher can arrive at this intimacy not by interrogating being from without, but by grasping the intertwining of being from within. And my point—which is arrived at by the method of studying being from within via studying what animal beings reveal to us, a method that still needs to be questioned-is that the logic of the impure invisible has its cognate or analogue in the logic of animal faces.

Third, the relation of the visible and the invisible points to a deeper Merleau-Ponteian theme, namely expression. For Merleau-Ponty, genuine expression is a paradoxical movement. As Len Lawlor puts it (finding a connection with Deleuze ${ }^{14}$ ), "[ $[\mathrm{t}]$ he paradox is that at once 'the expressed' does not exist outside of the expression and yet bears no resemblance to it" ("The End of Phenomenology" 17); what is ontologically at stake in expression is a ground that "must never borrow characteristics from what it grounds," that "must presuppose nothing of what it engenders" (22). At play in this view of expression is a critique of classic essentialism that runs as follows: Essentialism maintains that the visible is defined by and grounded in an essence behind the scenes. This leads to the supposition of a purely invisible essence that can yet be read from the visible that it grounds. This entails two contradictions: first, claiming that essence mirrors the visible, yet as purely invisible is not visible in what it mirrors; second, claiming that an essence that in fact merely duplicates the visible nonetheless functions as its independent explanatory ground. This echoes Bergson's problem with traditional dualism, namely, that Cartesian mind duplicates the body, rather than being utterly different from it (see esp. Bergson 
226-228). Essentialism operates with what I call an abstractly doubled visible: the visible scene is explained by a purely invisible register that is supposed to be different than what it explains, but really that register is just the visible reduplicated, in disguise, and so explanation is begged. Merleau-Ponty broaches this problem when he speaks of this as an "ontological diplopia" (VI $220 n / 166 n$ ) that would overlay the object with a separable layer of essences or ideas (as in Cartesian dualism). Instead, in VI, Merleau-Ponty pursues a very different sort of doubling, the intimate 'doubling' we spoke of above, in which being inflects itself with internal depth from within, so that being and its 'essence' are drawn never so close together, until finally being itself is internally double, chiasmic, inseparably being and 'essence,' yet without these two sides coinciding, such that the otherwise invisible essence of being is right there in being, like the "lining [doublure]" of a coat (VI 195/149), such that the visible is no mere front for its invisible, but is intimately implicated with its invisible. The redness is in the red light, is in the texture of the carpet and of the whole scene, yet is not the same as this scene (VI 173-5/131-3). Redness is the doublure of the scene, and red functions as the thing-face of redness.

So, as Lawlor (Implications of Immanence) observes, Merleau-Ponty's philosophy is a "mixturism" that mixes traditional conceptual poles (e.g., positive and negative, infinite and finite, being and essence) such that the poles must not be separated, yet must not coincide. This inseparable non-coincidence of being and essence, in which being is not given as some immediate spread of parts that are frontally external to one another, in which being is its own depths, which depths first of all gather being as being, is engendered by a movement kin to what Merleau-Ponty calls expression (what Merleau-Ponty, I think, later calls dehiscence). But this expressive mixturism is analogous to the logic of the face discussed above, in which, for example, a subject is engendered only through its predicates, which are not, however, there in 
advance of the subject. And so the invisible depths of being, like what is expressed in the expression, are not already given in advance, they are engendered, created, within the visible, they are an invisible of the visible, an invisible that is not transcendently beyond the visible. Being is not entirely determinate, is not ready made, since it always is—or rather always becomes-through its internal depths and distance from itself. On the other hand, being is not entirely indeterminate, for the visible always harbours its own invisible 'essence' within. Indeed, the visible would have no legibility, coherence, order, nothing that it is to be, if it were not the visible of its own internal invisible, if its visibility were not opened up by a deeper invisible.

We can now see why Merleau-Ponty can speak of "[t]he invisible of the visible" and of a Wesen (essence) that does not need to be grasped by a thought that would penetrate beyond the visible to a purely invisible double, why he can speak of "a Wesen that in principle is accessible as soon as the seeing is given" (VI 247/300-1)—a redness seen in the red. We can also see how this kind of ontology clearly challenges traditional essentialism and the traditional concept of essences, because it mixes essences into the dynamics of being, so an essence would no longer have the fixed lines of an already specified to-be or have-to-have-been. Essences no longer have to be essentially this way or that, since they are markers of a further but still open-ended to-be within the being of things, as Charlie's blink marks a further to-be of her body.

Finally, we can see how animal faces and their logic can serve as a template or exemplar for tracing and grasping the sort of logic central to an ontology of the invisible of the visible. We can also see how grasping the logic of faces in fact turns us toward the onto-logic of the invisible of the visible: trying to lay out the relation between the face and that of which it is the face is quite difficult within a classical frontal ontology of essences; the relation would be much more 
easily grasped in an anti-frontal ontology of internal relations, an ontology in which being and beings are their own invisible depths.

But still: Aren't faces and their logic just metaphors or analogies for the onto-logic of being? Is there really some deeper kinship between faces and being?

\section{The Kinship of Faces and Being: Animality in Embryo}

How is that faces can serve as exemplars for the structural logic of perceived things, even for the onto-logic of being? We might think that this is because of our thinking, subjectivity or perceptual apparatus. For example, we might think that (given the centrality and importance of faces to animals and their inherently inter-animal behaviour) face perception was crucial to our evolution as animals. So a kind of parsing logic first geared to faces carried over into our parsing of perceived things in general and thence informed the sort of logic we use, such that we are wont to experience perceived things as having a face-logic and to eventually think of being on such a model. On the contrary, I want to briefly suggest that our discovery of a face-logic in perceived things and being is not some subjective imposition or superficial evolutionary inheritance. Our having faces and thus evolving to be perceptually centred on them; things having faces; and being having a non-frontal logic kin to the logic of the face-these phenomena arise from an actual kinship, they are manifestations of one underlying logic. I argue that this underlying logic is rightly called a logic of animality.

This suggestion stems from thinking about current results and approaches in embryology. Again, the strategy here is to look to animal being for clues as to the way that nature and thence being move and structure themselves. The Cartesian philosophy severed the intimate relation between matter and form central to Aristotelian philosophy, so that matter ended up being 
entirely unformed, blank, a neutral substrate near naked of all properties. The consequence of this Cartesian move is that nature is conceptually cut up according to the demands of our thinking, according to our need for a clean break between form and content, which break allows for mathematical idealizations of nature, or allows nature to be modelled as the sort of machine built by a human engineer (who first abstracts a clear purpose for the machine and then builds the means to realize it, by linking up 'frontally' modularized functions, versus an evolution in which 'purposes' stand out only after a long muddling through, and functions too are muddled together and internally overlap). Once nature is modelled along these mathematical/mechanical lines animal embryogenesis becomes quite a problem-how to explain how a machine grows (see Smith)? And, within this mathematical/mechanical framework, once the modern synthesis discovers the gene as central mechanism of the evolution of species and develops mathematical/statistical approaches for analyzing the relation between genes and animal populations, the problem of embryogenesis is wrongly and unfortunately put on the back burner or taken as a problem that is minor in comparison to the successes of the genetic approach to evolution—even though for Darwin the embryogenesis of the individual and the evolution of species were of a piece, two modulations of the same plastic animal process (see Amundson). Further, when the problem of embryogenesis is first taken up within the genetic framework, it is conceptualized as the playing out of a genetic program: to exaggerate only a little, embryogenesis is conceived as the distribution of basically neutral matter according to an ideal form stored in the genes (see Kirschner and Gerhart; Carroll; Goodwin; Minelli; Amundson; Jablonka and Lamb). Bluntly, Darwin's central challenge had been to the idea of any sort of essence of species. But on the level of individual bodies, a logic of essences, a frontal ontology 
in which genetic programs stand behind bodily organization, snuck back into biology via the success of genetics.

Current science, specifically the program of evolutionary-developmental science, or "evodevo" (which puts evolution and development back together again, as with Darwin) exposes a challenge to this logic of frontality in the embryo itself. The problem of animal embryogenesis is how one totipotent egg cell turns into a host of different specialized cell types that are laid out and organized in the form of an adult animal. The classical genetic solution is to say that the genes entirely drive this process, that they entirely contain, as it were, the map of the organism and a specification of its differentia. The form is specified in advance and independent of the content. Evo-devo by no means contests the important role of genes, but shows how genes on their own could not solve the problem of embryogenesis. Genetic 'form' and bodily 'content' are interdependent, modulate one another, are not really separable from one another in terms of their real operation. For example, Brian Goodwin argues that the leaves of vascular plants and the limbs and digits of vertebrates acquire their radial or branching patterns (the variations of which are pervasive across and distinctive of vascular plant and vertebrate species) not through genetics merely but through tensions (due to inter-cell adhesion, etc.) endogenous to the very growth and multiplication of cells through which alone a single cell becomes a plant or animal. In the way that sand grains 'grow' into a conical pile without an essence of conicity being inscribed in the grains, the growth of cells within a plant or animal skin, just in virtue of growth dynamics, tends to certain forms of organization, although of course plant or animal growth is, unlike that of the sand pile, also modulated by genes. To give a different example, embryogenesis needs to account for the fact that, say, legs and not antennae grow at a certain spot in the animal body, and that the body spreads out so it has such spots in specific places. Evo-devo argues that this map of the 
body is not contained in the genes per se, but in the way that the growing body, as it spreads out, interacts with genetic signals spreading out through the body, such that these interactions end up specifying zones that call for cells growing in them to differentiate as, say, a leg versus an antenna (Kirschner and Gerhar; Carroll).

In other words, the animal body does not end up with a leg attached to a thoracic segment by way of there already being a body to which a thoracic segment is then added, to which a leg is then attached, as we would build or conceptualize a machine. The animal body does not grow by a mechanical logic of frontality, with parts spread out external to one another and then added together. The spread of the animal's growing body is one in which the growing parts always emerge within a dynamic relation that encompasses the whole, where the dynamics of this relation internally differentiate regions that will then differentiate as thorax and leg, such that these regions and these differentiations are always internal to one another's dynamics, such that the growth of a leg here is always counterpart in process to the growth of an antenna there (which is why mutations can happen at the level of legs and antennae exchanging places, etc.). Indeed, from the perspective of evo-devo the problem of embryogenesis is how to break up this overall dynamic of internality into distinctive regions, how to, for example, counter pleiotropy, the tendency a genetic signal would have to produce the same effect everywhere in the animal body.

The important point so far is that the development of the animal body is not governed by a genetic 'essence' but leverages the dynamics of cells. Now the structure of the face and its relation to the body and the body's animality are an outgrowth of these dynamics. If we trace the growth of the vertebrate face back into embryology (Sperber) we find that the face is no mere add-on to the vertebrate body, like a monitor added to a computer as an output mechanism, but is 
integrally implicated with the overall layout and formation of the vertebrate body and its muscular, skeletal and nerve systems (as noted at the outset). The face is no mere front, it is a deepening of what is already implied in the basic vertebrate body plan. And if we trace this plan back, we find it is implied in some of the most basic developmental movements of the vertebrate embryo. In the first grand movement of the vertebrate embryo, a single cell multiplies into a solid ball of cells. As this ball grows, outside fluid insinuates itself inward so that the ball forms a topologically closed surface, with outside fluid now encapsulated inside the ball. A topological distinction between inside and outside is thus engendered, but this does not yet correspond to a functional-biological distinction or relation of inside and outside, because there is no differentiation of function in the cells of the ball's skin, let alone a differential functioning with respect to insides versus outsides. In the next stage there are increases in cell size and differentiations of cell type, so that the surface of the envelope can be mapped into regions fated to form three germ layers whose distinction gives a matrix for the vertebrate body plan: the ectoderm, giving rise to skin and nerves; the mesoderm, giving rise to muscle, skeleton, circulatory and waste removal systems; and the endoderm, giving rise to the guts, lung and liver. But at this stage these regions are all on one physical surface with (in functional-biological terms) neither an inside nor outside. The regions are banded on the surface of the hollow embryo like red, white and blue bands on a child's balloon, and the animal is not yet structured and does not yet operate with an inside versus or outside (Wolpert; Minelli; Sperber).

The second grand movement of the vertebrate is gastrulation, in which the endoderm band ingresses to the inside of the envelope, dragging the mesoderm with it, and the ectoderm expands to envelop the outside surface. This drastic topological reorganization is what first gives the three germ layers their proper differential organization, and what first engenders a biologically 
functional differentiation and interrelation of inside and outside, with each of the germ layers embodying a different and complex relation of animal insides and outsides. To wit: The ectoderm layer (nerves and skin) takes the outside inside and gives a protective, exploratory and expressive outside to the inside; mesoderm (muscle, skeleton, circulation and waste removal) provides inside support for the body and its outsides, and removes inside waste to the outside; endoderm (guts, liver, lungs) digest the outside to turn it into inside. (Interestingly, the eardrum is a trimembrane composed of cells from each of these layers-a fact that might have perked Derrida's ears.) These embryological and topological movements, which also give rise to the face, once again leverage and are informed by basic processes of cell growth and adhesion wherein spread-out bits of matter are internally linked to one another though their movements and topology.

The face, then, is an outgrowth of an embryological process that physically and biologically differentiates and mixes insides and outsides in ways that challenge a frontal conception of the relation of inside and outside, interior and exterior. And this process works by means that challenge a logic of frontality that would separate form and content or think of parts as external to one another. Indeed, this process leverages cellular dynamics that point back to a deeper dynamis, power, of moving matter, a power of spread out movements of matter inhering in one another. On its finest levels it would seem that the growth of the embryo is not to be modelled on the lines of bricks being added to a building, but of waves or spheres of influence and relation spreading out, hollowing, turning inside out, deepening, and so on. Our analysis of the face showed that it challenges the logic of frontality and the division of inside and outside because the face is the outside of its own inside, it is the surfacing of its own interiorly inflected depths. In other words, for Merleau-Ponty the body makes itself "the outside of its inside and the 
inside of its outside" (VI 188-9/143-4). And we saw that this "mixturism" of outside and inside is strikingly manifest in the logic of the face. What I am suggesting here is that the face develops and evolves this way in virtue of processes that themselves challenge frontality. The face and body as making itself "the outside of its inside and the inside of its outside" have their genesis in a nature in which outsides and insides are already mixed. In a nature whose element is not bits of matter frontal to one another, but stuff inherently spread out through inter-influence with other stuff (a nature of what Merleau-Ponty would call flesh), things—accumulations of stuff—gather together and work by an anti-frontal facial logic. Perceived things acquire structure and exhibit thing-faces, and living things acquire structure and exhibit animal-faces, because the price of things and animals coming into being and hanging together is to have insides implicated in outsides and vice versa. And our perceptual relation to things (in virtue of which things have thing-faces for us) grows out of our common genesis with things in this anti-frontal logic of nature. The embryology of animal faces lets us read this point in some detail right within nature.

The logic of the animal face, in other words, is a sort of lens onto the logic of the development and evolution of which the animal face is a sediment. The face thus lets us see into a logic of nature that we might otherwise overlook. Put otherwise, the face is the visible of a logic of nature that might otherwise be invisible, or be concealed by our conceptual presuppositions. The logic that the face reveals is nothing other than: the logic of the invisible of the visible, a logic whereby visible spreads of stuff have an invisible internal excess by way of their being internal to one another in their spread. In other words, spread out stuff is not inert and neutral matter, because each part of it, like a part of the embryo, is implicated in other parts, and in virtue of the dynamics of this implication, stuff has something more to it than is visible on first glance. A piece of stuff can gain a new kind of determinacy beyond its present determinacy by 
way of this internal implication. There is a sort of hollow or underdeterminacy in stuff, yet stuff is not entirely indeterminate either, for what hollows it out is a logic that internally and movingly binds it to other stuff and thus limits it. This anti-frontal logic is what we first found in the animal face and then in the development of the animal. It is a logic of dynamic links that organize themselves through their very movement, the sort of organizing in movement that is characteristic of animal beings as manifesting animality. For this reason I claim that it is rightly called a logic of animality.

Our tendency has been to conceptualize nature as an array of parts spread out external to one another, in already given dimensions of space, time, or space-time, dimensions external to stuff. The logic of animality here being identified challenges this tendency, for it is a logic in which bits of stuff have an internality to one another, a moving affiliation, a primordial spreadoutness prior to their being arrayed in space and time, in which the animate movement of bits of stuff in relation to other bits is generative of the differentiation of determinate parts and their spread-outness, with all this taking place in a sphere of animation that is itself generated by this very movement of differentiation - in the way that the formation of the face is generative of the distance between the face and its body, of the 'facial space' in which bodies appear as bodies of faces.

It seems to me that Merleau-Ponty is heading in something like this direction. First: In classical philosophy the question of how there is something general and how there are general patterns of nature would be handled by way of essences, ideas and so on, such that, for example, the account of all this-here stuff being sulphur is cashed out in terms of all of it resembling an ideal of sulphur. But as Renaud Barbaras observes ("Merleau-Ponty and Nature" 35), in an unpublished piece by Merleau-Ponty on "dynamic morphology," Merleau-Ponty writes that this 
question is badly put for "it is the same sulfur, and not the same idea of sulfur, which is here and there." In other words, stuff forms up as sulphur spread out in nature not because another piece of matter is knocked off or shaped according to an existing essential template and then added on to nature. Rather, nature as inherently spread out and spreading out in an anti-frontal way, through its internal excess, inflects itself as sulphur across its spread, in the manner of genetic signals spreading through an embryo in interaction with the spread of body inflecting a leg here and there. The legs are not of a piece in virtue of resembling some abstract ideal or essence, but in virtue of being generated as inflections of one inherently spread out process. Their sticking up here and there as resembling one another in a seemingly external way is a visible artefact of an invisible underlying internality. Similarly with the bits of sulphur. (This way of thinking about nature resonates with the physicist David Bohm's thought of an "implicate order" of the universe, wherein the determinacy of the universe arises through a logic of internal implications across nature.)

Second, in the lectures on institution, in a discussion of animality (animalité) and the embryo (specifically, in an analysis of results by Ruyer about the processes behind legs becoming left or right legs), Merleau-Ponty writes that the organism is specified by a "plasticity" that is nonetheless "limited by issues of place," so that the fate of parts is an institution that "is absolutely nothing given along with innate internal structure" yet "is never independent of the given (time and place)" (LI BN 16). Here Merleau-Ponty is speaking against a frontal logic of essences and is arguing that time and place are crucial to the embryo yet are not wholly determinative of it. He then writes that there is "no precise limit between organization and life (Bergson)" and that causality and determination are "releases" of "trans-spatial feed-backs" in which "what acts in returning upon the cause" is "no mere divergence [écart] between a result 
and a material goal" but "a divergence between a result and an "idea" (16). I think he is seeing that there is no wholly specified plan/idea for the embryo given in advance, rather the logic of the embryo is the logic of a spread out process internally inflecting its own depths, such that the ongoing processual result of this inflection 'doubles' or shadows itself with its own 'idea'-like a moving bicycle that (in diverging or precessing from its line of movement in such a way as to be pulled back to it) shows that its movement is 'doubled' with an 'ideal' trajectory. Thus the 'idea' of the organism emerges in a sort of internal divergence between an ongoing result and its internally inflected idea, an idea that only becomes manifest in that result and in that divergence, a new kind of idea that is thus an invisible of a visible. It seems that Merleau-Ponty is here and also in the lectures on nature ${ }^{15}$ preparing himself to see a kinship between the logic of animality whereby the embryo develops into an animal, and the logic of being as becoming through écart, chiasm, dehiscence, reversibility, and an invisible of the visible.

In the lectures on institution Merleau-Ponty calls this movement of écart, wherein a result deepens into and engenders the idea that first motivates it, institution (which term relates to but contrasts with his earlier notion of expression). Perhaps we could conclude, then, by saying that the animal face is an institution: Charlie's blink institutes her body as animal and friendly, and it institutes a possibility of interspecies friendliness. In doing so, her face, its relation to her body, her face's relation to her development and her species evolution, all show that the institutional logic of the face, because literally growing out of the evolving movements of nature and being, is kin to the deeper logic of institution, of "trans-spatial feed-backs" through which spread out stuff can internally diverge and acquire depths that first of all reveal being's internal excess. But this excess inherent within being is thence kin to the excess of animality inherent within the animal face, and the logic of being's excess is kin to the logic of spread out parts gathering depths that is 
manifest in the animal face and in its embryological development. Being affords institutions such as evolved animal bodies, animal faces, animal expression, our expressions, our linguistic institutions, our meanings, our philosophies_-institutions that gather being as having its own internal coherence-because being manifests a logic of animality, in which spread out movements are logically prior to the externally differentiated parts, spaces and times that are so central to traditional frontal ontologies. Institution and thence animality, in other words, deepen Merleau-Ponty's earlier logic of expression by rooting it in a logic of being, rather than just in subjectivity.

So in the animal face as the visible of its invisible, and in the invisible of the visible animal face, we catch a glimmer of an onto-logic of being, an ontology of animality that challenges traditional frontal ontologies.

\section{Notes}

${ }^{1}$ Various portions and ideas from this paper were presented at the Merleau-Ponty Circle and Northern Arizona University in 2005, and at Stony Brook University in 2004. I would like to thank members of the audience and readers of the paper for their helpful comments, in particular John Russon, Ed Casey, Emilia Angelova, Beata Stawarska, David Ciavatta, Kym Maclaren, Gregory Recco, and Susan Bredlau. I would also like to thank Astrida Neimanis for helpful suggestions.

2 Merleau-Ponty's texts will be cited using the abbreviations so far listed, with the French pagination followed by the English, using the following editions: $S B$ 1942/1965; PhP 1945/1962/2002; VI 1964/1968. For the lectures on institution (LI), the editions are: 2003 (referenced, where possible, using the BN [Bibliothèque Nationale] page numbers in Lefort's edition)/1970 (the English translates only the resumé of the course); and the editions for the lectures on nature $(L N)$ are: 1995/2003.

${ }^{3}$ Also see PhP on the experience error (11/5/5), and Barbaras, Le tournant de l'expérience.

${ }^{4}$ Durée is of course peculiar as an arche because it is not already given principle, but rather a becoming. 
${ }^{5}$ Here I will be focusing on the face as visual. This is because the visual dimension especially emphasizes structures that stretch over distances. However, the logic of the face that is articulated below also belongs to the tangible, the olfactory and the gustatory. In the tangible we can feel that what we are touching is just a thing-face of that thing; e.g., in feeling the rigid surface of the soup-can we feel that it is not its sloshing contents, which are the invisible but present insides of this surface. While we can feel this in touch, vision makes this hiddenness explicit in a glance, it shows us what is hidden more directly. We can also, of course, smell the animal's fear in the animal's scent. For extraordinary observations about the human face as both being central to and transformed by the experience of blindness-as figuring in the non-visual world-see Hull.

${ }^{6}$ Faces are of course central to the lives of human animals: the face has long been a topic of interest to poets and philosophers (from Plato to Levinas) and of course is central to visual and plastic art. As a famous study by Meltzoff and Moore shows, infants latch on to faces just minutes after birth, and faces remain central to us thereafter; see, e.g., Cohn and Tronick; Fogel, Messinger, Dickson and Hsu; Kaye and Fogel; Lamb, Morrison and Malkin; Watson, Hayes, Vietze and Becker. It has also been shown that our brain has evolved areas, the activity of which is specialized for faces and facelike things. See Kanwisher and Moscovitch; Gauthier and Logothetis; Rhodes, Byatt, Michie and Puce; Guathier, Skularski, Gore and Anderson. On human perception of faces and their centrality to human life, also see Cole About Face, "On Being 'Faceless'"; Bruce and Young; Bruyer.

${ }^{7}$ For an effort at giving an 'insider's view' of animal perception see Grandin.

${ }^{8}$ See $S B \quad 175 / 162$ and see $P h P$ 249/215/250, 278/240/279, 492/431/501. The "hollow" is a pervasive theme of $V I$ (mentioned around 20 times), including discussion of embryogenesis as preparing a hollow within the organism (VI 287/234), and it plays a similar role in $L N$; see, e.g., LN 302/238.

${ }^{9}$ See, for example, his point that "The phenomenon of life appeared... when a piece of extension, by the disposition of its movements and by the allusion that each movement makes to all the others, turned back upon itself and began to express something, to manifest an interior being externally" (SB 175/162).

${ }^{10}$ See George Franju's Eyes Without a Face, John Frankheimer's Seconds, John Woo's Face/Off, or the moment in the autopsy documented in Stan Brakhage's The Act of Seeing with One's Own Eye's when the skin of the face is peeled away from the body.

${ }^{11}$ Especially the passage from the sun to the good, through the discussion of the divided line, hypothesis and dialectic, which is then echoed in the image of the passage out of and back into the cave. On the centrality to Plato of telling the difference between things and their real look, see González. 
${ }^{12}$ For example, as González argues, the good is the most important idea, since it is the idea of a difference between something and its idea, between the visible and its invisible. But we should observe that the good is imaged with the sun, something so burningly visible it is invisible to the human eye. The good is invisible because is it so blindingly visible, all too visible, rather than being entirely invisible. And if the good concerns the difference between the visible and the invisible, we would have to ask if it really can be purely invisible, as is usually claimed, or whether it must not of itself (in telling the difference between the visible and the invisible) overflow into the visible, as the neo-Platonist Plotinus might put it (or whether, alternately, it appears only in its difference from the visible).

${ }^{13}$ On the role of kinaestheses in Husserl, see Landgrebe, Sheets-Johnstone.

${ }^{14}$ It remains for another paper to pursue the possible links and divergences between MerleauPonty and Deleuze on faces, expression and embryology.

15 Although this aspect of $L N$ cannot be studied here, it is quite apparent in his analysis of ontogenesis in Ruyer and Driesch (LN 293-304/229-240), in which Merleau-Ponty urges that an account true to the phenomena requires a "metaspatial" conceptual framework (in which the space of organization is subsequent to what is organized, rather than the organization being given in space or being specified spatially) and a philosophy of entelechies. In other words, in $L N$ the phenomenon of animal embryogenesis provides clues to a different ontology.

\section{Works Cited}

Amundson, Ron. The Changing Role of the Embryo in Evolutionary Thought: Roots of EvoDevo. Cambridge: Cambridge University Press, 2005.

Barbaras, Renaud. Desire and Distance. Trans. Paul B. Milan. Stanford: Stanford University Press, 2006.

—. Le désir et la distance: Introduction à une phénoménologie de la perception. Paris: J. Vrin, 1999.

—. Le tournant de l'expérience: Recherches sur la philosophie de Merleau-Ponty. Paris: J. Vrin, 1998.

—. "Life and Perceptual Intentionality." Research in Phenomenology 33 (2003): 157-66.

—. "Merleau-Ponty and Nature." Research in Phenomenology 31 (2001): 22-38. 
-. "The Movement of the Living as the Originary Foundation of Perceptual Intentionality." Naturalizing Phenomenology: Issues in Contemporary Phenomenology and Cognitive Science. Eds. Jean Petitot, et al. Stanford: Stanford University Press, 1999. 525-38.

—. "Perception and Movement: The End of the Metaphysical Approach." Chiasms: MerleauPonty's Notion of Flesh. Eds. Fred Evans and Leonard Lawlor. Albany: State University of New York Press, 2000. 77-87.

—. Vie et intentionalité: Recherches phénoménologiques. Paris: Vrin, 2003.

Behnke, Elizabeth A. "From Merleau-Ponty's Concept of Nature to an Interspecies Practice of Peace." Animal Others: On Ethics, Ontology and Animal Life. Ed. H. Peter Steeves. Albany: State University of New York Press, 1999. 93-116.

Bergson, Henri. Matter and Memory. 1896. Trans. N.M. Paul and W.S. Palmer. New York: Zone Books, 1991.

Bohm, David. Wholeness and the Implicate Order. New York: Routledge, 2002.

Bruce, Vicki, and Andy Young. In the Eye of the Beholder: The Science of Face Perception. Oxford: Oxford University Press, 1998.

Bruyer, Raymond, ed. The Neuropsychology of Face Perception and Facial Expression. Hillsdale, New Jersey: Lawrence Erlbaum, 1986.

Carroll, Lewis. Alice's Adventures in Wonderland. London: Puffin Books, 1994.

Carroll, Sean B. Endless Forms Most Beautiful: The New Science of Evo Devo. New York: W.W. Norton \& Company, 2005.

Cohen, Irun R., and Henri Atlan. "Limits to Genetic Explanations Impose Limits on the Human Genome Project." Encyclopedia of the Human Genome. Ed. David N. Cooper. London: Nature Publishing Group, 2002.

Cohn, Jeffrey E., and Edward Z. Tronick. "Mother-Infant Face-to-Face Interaction: The Sequence of Dyadic States at 3, 6, and 9 Months." Developmental Psychology 23.1 (1987): 68-77.

Cole, Jonathan. About Face. Cambridge, Mass.: MIT Press, 1999.

—. "On Being 'Faceless': Selfhood and Facial Embodiment." Models of the Self. Eds. Shaun Gallagher and Jonathan Shear. Thorverton, UK: Imprint Academic, 1999. 301-18. 
Fogel, Alan, et al. "Posture and Gaze in Early Mother-Infant Communication: Synchronization of Developmental Trajectories." Developmental Science 2.3 (1999): 325-32.

Fox Keller, Evelyn. The Century of the Gene. Cambridge, Mass.: Harvard University Press, 2000.

-. Making Sense of Life: Explaining Biological Development with Models, Metaphors and Machines. Cambridge, Mass.: Harvard University Press, 2002.

-. Refiguring Life: Metaphors of Twentieth-Century Biology. New York: Columbia University Press, 1995.

Gauthier, Isabel, and Nikos K. Logothetis. "Is Face Recognition Not So Unique After All?" Cognitive Neuropsychology 17 (2000): 125-42.

González, Francisco J. Dialectic and Dialogue: Plato's Practice of Philosophical Inquiry. Evanston, IL: Northwestern University Press, 1998.

Goodwin, Brian. How the Leopard Changed Its Spots: The Evolution of Complexity. Princeton: Princeton University Press, 2001.

Grandin, Temple. Animals in Translation: Using the Mysteries of Autism to Decode Animal Behavior. New York: Scribner, 2005.

Guathier, Isabel, et al. "Expertise for Cars and Birds Recruits Brain Areas Involved in Face Recognition." Nature Neuroscience 3.2 (2000): 191-97.

Guthrie, W.K.C. A History of Greek Philosophy. Vol. 1. Cambridge: Cambridge University Press, 1962.

Hull, John M. On Sight and Insight: A Journey into the World of Blindness. Oxford: Oneworld Publications, 1997.

Husserl, Edmund. Experience and Judgment: Investigations in a Genealogy of Logic. Trans. James S. Churchill and Karl Ameriks. Evanston: Northwestern University Press, 1973.

Jablonka, Eva, and Marion J. Lamb. Evolution in Four Dimensions: Genetic, Epigenetic, Behavioral, and Symbolic Variation in the History of Life. Life and mind. Cambridge, Mass.: MIT Press, 2005.

Jonas, Hans. The Phenomenon of Life: Toward a Philosophical Biology. Evanston, IL: Northwestern University Press, 1966. 
Kanwisher, Nancy, and Morris Moscovitch. "The Cognitive Science of Face Processing: An Introduction." Cognitive Neuropsychology 17 (2000): 1-11.

Kaye, Kenneth, and Alan Fogel. "The Temporal Structure of Face-to-Face Communication Between Mothers and Infants." Developmental Psychology 16.5 (1980): 454-64.

Kirschner, Marc W., and John C. Gerhart. The Plausibility of Life: Resolving Darwin's Dilemma. New Haven: Yale University Press, 2005.

Lamb, Michael E., Dian C. Morrison, and Catherine M. Malkin. "The Development of Infant Social Expectations in Face-to-Face Interaction: A Longitudinal Study." Merril-Palmer Quarterly 33.2 (1987): 241-54.

Landgrebe, Ludwig. "The Phenomenological Concept of Experience." Philosophy and Phenomenological Research 34.1 (1973): 1-13.

Lawlor, Leonard. "The End of Phenomenology: Expressionism in Deleuze and Merleau-Ponty." Continental Philosophy Review 31 (1998): 15-34.

-. Implications of Immanence: Toward a New Concept of Life. New York: Fordham University Press, 2006.

Levinas, Emmanuel. The Theory of Intuition in Husserl's Phenomenology. 1930. Trans. André Orianne. Second ed. Evanston, Illinois: Northwestern University Press, 1995.

Lloyd, Seth. Programming the Universe: a Quantum Computer Scientist Takes on the Cosmos. New York: Knopf, 2006.

Maclaren, Kym. "Life is Inherently Expressive: A Merleau-Pontian Response to Darwin's The Expression of the Emotions in Man and Animals." Chiasmi International 7 (2005): 24160.

Meltzoff, Andrew N., and Keith M. Moore. "Imitation of Facial and Manual Gestures by Human Neonates." Science 198 (1977): 75-78.

Merleau-Ponty, Maurice. "Eye and Mind." Trans. Carleton Dallery. The Primacy of Perception. Evanston, IL: Northwestern University Press, 1964. 159-90.

—. L'institution et la passivité: Notes de cours au Collège de France (1954-1995). Paris: Editions Belin, 2003.

—. La nature: notes, cours du Collége de France. Paris: Seuil, 1995.

—. Le visible et l'invisible. Paris: Galimard, 1964. 
-. Nature: Course Notes from the Collége de France. Trans. Robert Vallier. Evanston, Ill.: Northwestern University Press, 2003.

—. Phénoménologie de la perception. Paris: Galimard, 1945.

-. Phenomenology of Perception. 1945. Trans. Colin Smith. Atlantic Highlands, New Jersey: The Humanities Press, 1962.

-. "The Primacy of Perception and Its Philosophical Consequences." Trans. James M. Edie. The Primacy of Perception. Evanston, IL: Northwestern University Press, 1964. 12-42.

—. The Structure of Behaviour. 1941. Trans. Alden L. Fisher. London: Methuen, 1965.

Minelli, Alessandro. The Development of Animal Form: Ontogeny, Morphology, and Evolution. Cambridge, UK: Cambridge University Press, 2003.

Portmann, Adolf. Animal Camouflage. Ann Arbor: University of Michigan Press, 1962.

-. Animal Forms and Patterns: A Study of the Appearance of Animals. Trans. Hella Czech. New York: Schocken Books, 1967.

—. Animals as Social Beings. Trans. Oliver Coburn. London: Hutchinson, 1961.

-. Essays in Philosophical Zoology: The Living Form and the Seeing Eye. Trans. Richard B. Carter. Problems in contemporary philosophy. v. 20. Lewiston: E. Mellen Press, 1990.

Prigogine, I., and Isabelle Stengers. The End of Certainty: Time, Chaos, and the New Laws of Nature. 1st Free Press ed. New York: Free Press, 1997.

Rhodes, Gillian, et al. "Is the Fusiform Face Area Specialized for Faces, Individuation, or Expert Individuation?" Journal of Cognitive Neuroscience 16 (2004): 189-203.

Ruxton, Graeme D., Thomas N. Sherratt, and Michael P. Speed. Avoiding Attack: The Evolutionary Ecology of Crypsis, Warning Signals and Mimicry. Oxford: Oxford University Press, 2004.

Schneider, Eric D., and Dorion Sagan. Into the Cool: Energy Flow, Thermodynamics, and Life. Chicago: University of Chicago Press, 2005.

Seife, Charles. Decoding the Universe. New York: Viking USA, 2006.

Sheets-Johnstone, Maxine. The Primacy of Movement. Amsterdam: John Benjamins Publishing Company, 1999. 
Smith, Justin E. H. The Problem of Animal Generation in Early Modern Philosophy. New York: Cambridge University Press, 2006.

Smolin, Lee. The Life of the Cosmos. New York: Oxford University Press, 1997.

Sperber, Geoffrey H. Cranio Facial Development. Hamilton: BC Decker Inc., 2001.

Waldenfels, Bernhard. "The Paradox of Expression." Chiasms: Merleau-Ponty's Notion of Flesh. Eds. Fred Evans and Leonard Lawlor. Albany: SUNY Press, 2000. 89-102.

Watson, John S., et al. "Discriminative Smiling to Orientations of Talking Faces of Mother and Stranger." Journal of Experimental Child Psychology 28 (1979): 92-99.

Woese, Carl R. "A New Biology for a New Century." Microbiology and Molecular Biology Reviews 68 (2004): 173-86.

Wolfram, Stephen. A New Kind of Science. Champaign, IL: Wolfram Media, 2002.

Wolpert, Lewis. Principles of Development. 2nd ed. Oxford: Oxford University Press, 2002. 